\title{
1980 ASA ANNUAL MEETING
}

The 1980 ASA Annual Meeting will be held at the Benjamin Franklin Hotel in Philadelphia from October 15-18. The program director is Professor William B. Schwab, Department of Anthropology, Temple University, Philadelphia, Pennsylvania 19122. The central theme will be "Change and Contrast: New Directions and Traditional Ties in Africa," It is hoped that participants will direct their papers to examining both traditional patterns and emerging new social structures, institutions, religious groupings, and economic systems.

The meetings are also concerned with general problems of Africa, and prospective participants are encouraged to submit paper and panel suggestions on other themes. General requirements will apply to all papers and panels. Each panel suggestion must be accompanied by a general abstract of the panel, indicating its objectives, goals, and members. Each participant must submit an abstract of his/her paper. Abstracts may be sent in by the panel chairman or individually. We are assuming that each panel will have five participants and one or two discussants. We expect papers to be limited to a maximum of twenty minutes in oral presentation.

AFRICAN STUDIES NEWSLETTER. Vol. XII, Nos. 5 \& 6, Oct./Dec. 1979. Editor: Claudia Bruce. Published six times a year by the African Studies Association. Contributions should be sent to African Studies Newsletter, Epstein Service Building, Brandeis University, Waltham, Mass. 02154. Receipt of the African Studies News/etter, the African Studies Review, and /ssue is automatic with membership in the African Studies Association. Domestic claims for non-receipt of issues must be made within six months of the month of publication-overseas claims must be made within one year. [Members are advised that the post office does not forward periodicals. To avoid loss of publications or premature suspension of membership, members should notify the Association in writing at the time of any change of mailing address.] Copies of the African Studies News/etter damaged in the mail will be replaced without charge.

\section{AFRICAN STUDIES ASSOCIATION}

Epstein Service Building

Brandeis University

Waltham, Mass. 02154

\section{RETURN REQUESTED}

\section{BULK RATE}

U.S. POSTAGE

PAID

Ann Arbor, Mich. Permit No. 195 